\title{
Analysis of Preferences in the Use of Fixed-Doses Combinations Antihypertensive Drugs in the Regions of Far-Eastern Federal District
}

This article was published in the following Dove Press journal: ClinicoEconomics and Outcomes Research

\author{
Mariia Sergeevna Soboleva $\mathbb{D}^{\prime}$ \\ Ekaterina Efimovna \\ Loskutova iD $^{2}$ \\ 'Department of Pharmacy and \\ Pharmacology, The Far-Eastern State \\ Medical University, Khabarovsk, 680000, \\ Russian Federation; ${ }^{2}$ Peoples' Friendship \\ University of Russia Medical Faculty, \\ Moscow II7198, Russian Federation
}

Correspondence: Mariia Sergeevna Soboleva

Email martimser@mail.ru
Background: Diseases characterized by elevated blood pressure are the most frequently diagnosed pathology among socially significant diseases in the Russian Federation. According to clinical recommendations of the Russian Medical Society for Arterial Hypertension 2010-2019, the use of two and more component drugs improves the compliance of patients to treatment. The purpose of this study was a comparative analysis of preferences in the usage of combined antihypertensive drugs in ten regions of the Far Eastern Federal District (FSD).

Materials and Methods: Intra-group analysis of data on the sale of antihypertensive drugs in pharmacy organizations (162 drugstores) for the period 2018 was carried out in the 10 regions of the FSD. The sample is uneven due to the difference in total number of drugstores in the regions. The sample was random. Pharmacies were in urban and rural areas. The total purchase of all defined daily doses of all antihypertensive drugs was taken as $100 \%$. Then, fixed-dose combinations were selected. The share of each drug in the sales structure was then calculated. Kruskal-Wallis criterion was used for determining the differences in the structure of acquisition of drugs between the regions. The Spearman's rank correlation and factor analysis were used for determining the correlation between the drug's acquisition structure and the FSD region.

Results: Two-component drugs are most in demand in the Amur region $-15.2 \%$ and Zabaykalsky Krai $-12.3 \%$, and the lowest demand in the Sakhalin region $-5.25 \%$ and Magadan region $-6.5 \%$. The largest sales indicators of three-component drugs were observed in the Zabaykalsky Krai $-1.2 \%$ and the Republic of Buryatia $-1.0 \%$. The most acquired combinations were atenolol+chlorthalidone, valsartan+amlodipine, losartan+hydrochlorothiazide, perindopril/lisinopril/ramipril+amlodipine, perindopril+indapamide.

Conclusion: Group leaders may vary depending on the region, which is due to the preferences of medical specialists. However, the differences are not significant, which proves the unity of approaches to combined drug therapy of arterial hypertension.

Keywords: arterial hypertension, fixed-dose combinations, pharmaceutical market, Far Eastern Federal District, Russian Federation, acquisition of drugs, intra-group analysis

\section{Introduction}

Diseases characterized by elevated blood pressure are the most frequently diagnosed pathology among socially significant diseases in the Russian Federation. Thus, since 2010 , the indicator of incidence (the first time is revealed patients by 100,000 people), increased by $70 \%$ and in 2018 amounted to 1047.9. The Far Eastern Federal District (FSD) is characterized by a rather favorable epidemiological situation. The average 
incidence rate in the regions is $666.43 \pm 85.77 .{ }^{1} \mathrm{~A}$ constant increase in blood pressure (above 140/90) can lead to the development of severe cardiovascular complications such as stroke, heart failure, coronary events. ${ }^{2,3}$ The necessity to prescribe antihypertensive therapy is confirmed by data of meta-analyses and randomized clinical trials. ${ }^{4-7}$

In most cases, combined antihypertensive therapy, even at low doses, is more effective than monotherapy at greatest doses, primarily due to the combined effect on the various mechanisms of disease pathogenesis (suppression of the renin-angiotensin-aldosterone system, relaxation of the vessels, suppression of sympathetic innervation, reduction of circulating blood volume and heart load). Besides, the use of several drugs, in smaller doses, helps to reduce the risk of side effects (dry cough, metabolic disorders, reflex tachycardia, etc.). ${ }^{8-11}$

The usage of combination therapy is possible in two versions: combinations of monocomponent drugs and fixeddose combinations. However, according to clinical recommendations of the Russian Medical Society for Arterial Hypertension 2010-2019, the use of two and more component drugs "is recommended to all patients with arterial hypertension, as the reduction in the number of daily tablets improves the compliance to treatment." The main therapeutic classes that are prescribed as "first line" drugs are: angiotensin-converting enzyme inhibitors (ACE inhibitors), angiotensin II receptor blockers (ARBs), calcium channel blockers (CCB), diuretics (D) and $\beta$-blockers. Most of these pharmacological groups combine well, depending on the patient's anamnesis, the presence of additional indications and contraindications. In the Russian Federation, acquisition of drugs is not included in state health insurance, so the purchase of medicines for outpatient therapy is carried out, for most people, for their own money. The prescription of the drugs takes place according to the international nonproprietary name. The patient decides, which trade name to buy, already in the drugstores. As a result, many doctors often prescribing fixed-dose combinations represented by many generic drugs, because the price for them is generally lower, so they are more available to patients for regular usage. Preferences of medical specialists can vary significantly in different regions of the Russian Federation, so the purpose of the study is to compare preferences in the use of combined antihypertensive drugs in ten regions of the FSD. This study is carried out for the first time in the FSD and demonstrates the degree of implementation of the results of modern studies about fixeddose combinations in real clinical practice and therapy.

\section{Materials and Methods}

Data on the sale of antihypertensive drugs in pharmacy organizations for the period 2018 were used for the analysis in Kamchatsky Krai $(\mathrm{KK})(\mathrm{n}=6)$, Magadan region (MR) $(n=2)$, Khabarovsky Krai (KHK) $(n=66)$, Sakhalin region $(\mathrm{SR})(\mathrm{n}=24)$, Primorsky Krai $(\mathrm{PK})(\mathrm{n}=32)$, Republic of Saha (Yakutia) (RS) $(\mathrm{n}=11)$, Jewish Autonomous Region (JAR) ( $=3$ ), Amur Region (AR) $(n=10)$, Republic of Buryatia (RB) $(n=3)$, Zabaicalsky Krai $(Z K)(n=5)$. According to "Alpha research \& marketing", the total number of pharmacy organizations in the analyzed regions was $2696 .{ }^{12}$ The sample is uneven among regions due to the difference in territory, population density and, respectively, number of drugstores $\left(\mathrm{r}_{\mathrm{s}}={ }_{0.56}\right.$ $0.905_{0.98} ; p=0.002$; Figure 1). The sample was random. Pharmacies were in urban and rural areas. All drugstores

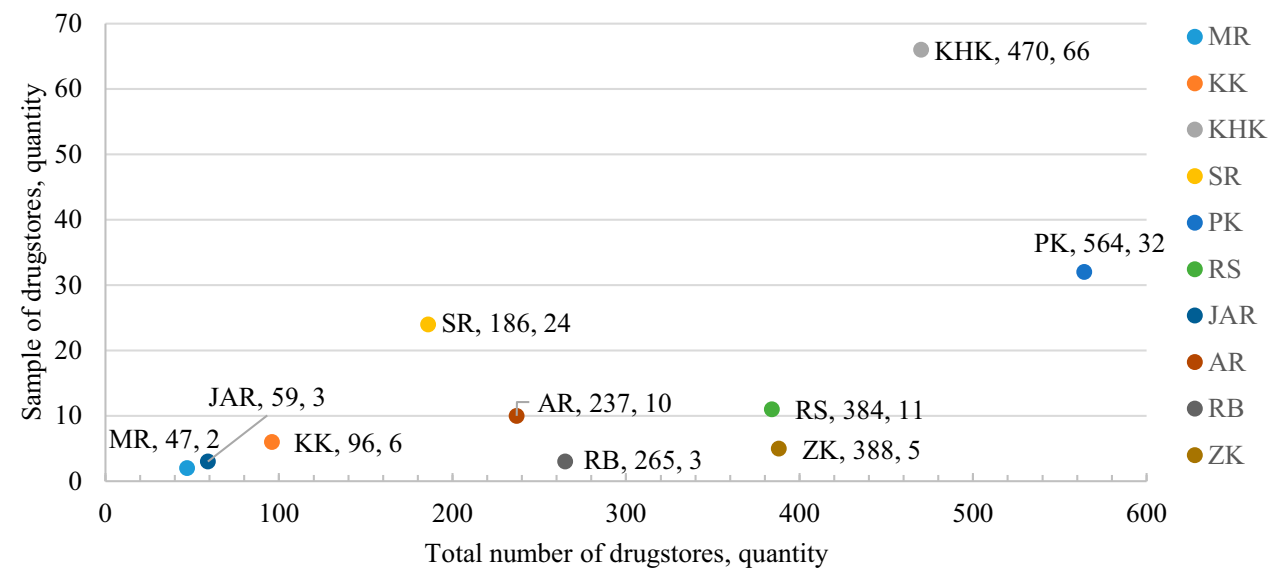

Figure I Correlation of the sample and the total number of the pharmacies in FSD regions.

Note: S - Statin. 
were computerized, with stable communication and modern software ("1C Pharmacy" programs), equipped with own bar-coding`s system, scanner for reading marking and elimination of errors in the work of the specialist. Drugstores had the system of internal quality control and advanced training of specialists. Totally, pharmacies had a significant share in the trade turnover in the pharmaceutical market of the FSD of $12-36 \%$ depending on the sum regions. The lower coverage of pharmacies in the Republic of Buryatia and the Zabaicalsky Krai is due to the entry of these regions with the composition of the FSD only in 2018. This sample is enough to provide with $95 \%$ probability the error $7.5 \%$ (calculation using an on-line sample calculator), which is permissible for a sociological study in RF. $^{13}$

Based on the obtained data, a general sales database in natural equivalent (by number of packages) was created using Microsoft Office Excel 2015. The next step was to calculate the total sales of defined daily dose (DDD) of all international nonproprietary names. DDD “is assumed average maintenance dose per day for a drug used for its main indication in adults". For fixed-dose combinations, the World Health Organization rule " 1 tablet is DDD for all once-daily drugs and DDD for twice-daily and threedaily drugs is 2 tablets and 3 tablets, respectively," was used. ${ }^{14}$ The total purchase of all DDD antihypertensive drugs was taken as $100 \%$. Then, fixed-dose combinations were selected. The share of each drug in the overall sales structure was then calculated. "Data Analysis" and "Subtotals" were used. Statistical analysis of the data was performed using IBM SPSS Statistics 25 software (Russian-language version) using the non-parametric Kruskal-Wallis criterion, as well as the Spearman's rank correlation and factor analysis. Kruskal-Wallis criterion was used for determining the differences in the structure of acquisition of drugs between the regions (several independent samples). The null hypothesis about median equality was rejected at $\mathrm{p}<0.05$. The Spearman's rank correlation and factor analysis were used for determination of the correlation between the drug's acquisition structure and the FSD region. Regions and drugs were coded into nominal scale. The correlation was considered significant $\mathrm{p}<0.05$. The threshold was a significance level of 0.05 .

\section{Results and Discussion}

The total indicators of acquisition of fixed-dose combinations in the regions are presented in Figure 2. The largest shares of fixed-doses combinations were observed in AR - 15.3\% and $\mathrm{ZK}-13.5 \%$. The most rarely fixed-dose combinations were sold in SR $-5.3 \%$ and MR $-6.6 \%$. Thus, the purchase of

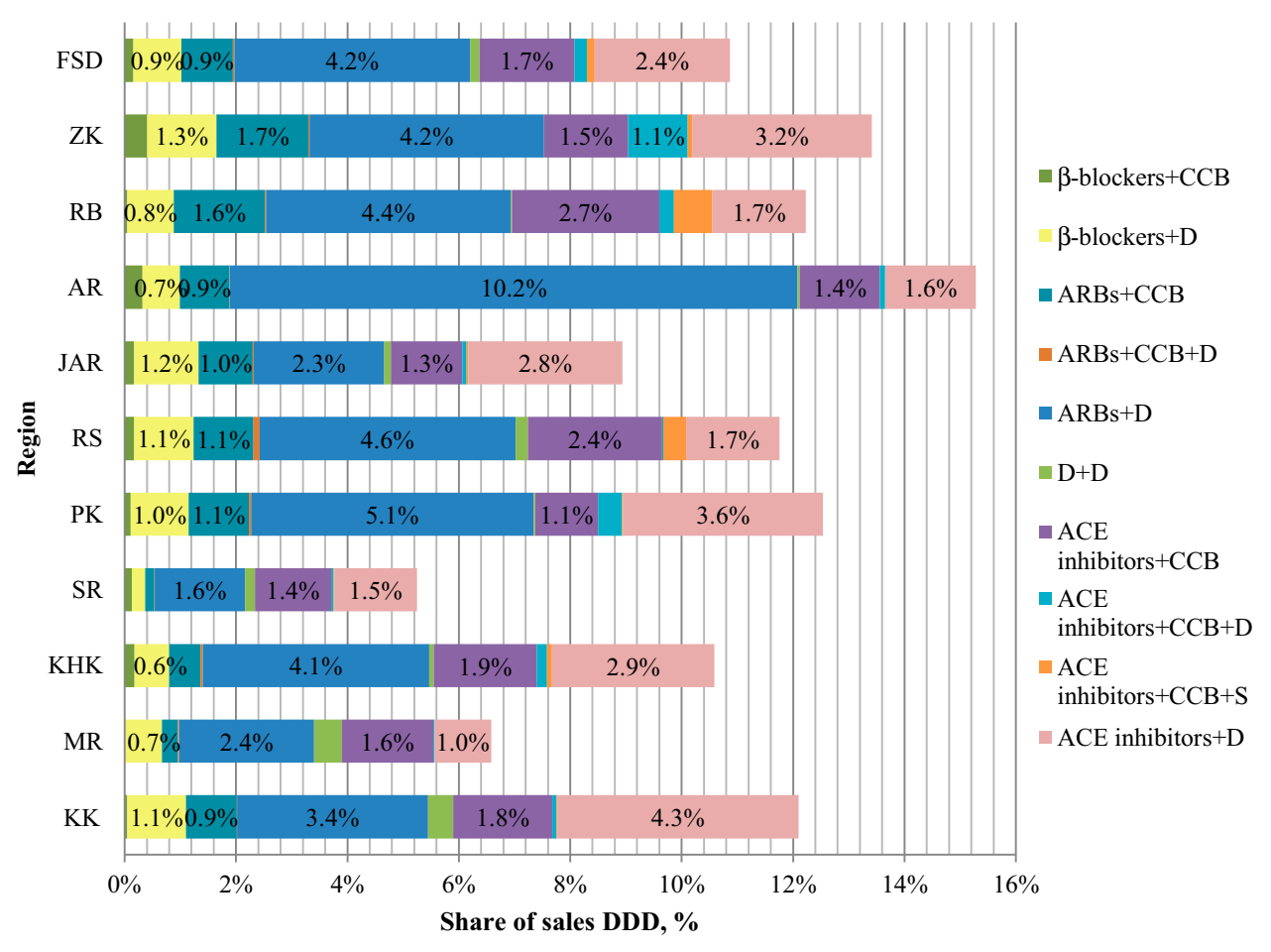

Figure 2 Structure of realization of DDD fixed-dose combinations in regions of the FSD. 
combined drugs in the subjects of FSD remains at a low level, despite the wide assortment presented in pharmaceutical markets. The most sought-after fixed-doses combinations in FSD regions are combinations of ACE inhibitors with diuretics/CCB as well as ARBs with diuretics.

Maximum sales indicators of $\mathrm{ARBs}+$ diuretic combinations were observed in $\mathrm{AR}-10.2 \%$, minimum $-1.6 \%$ in $\mathrm{SR}$. With the combination of ACE inhibitors+CCB the largest shares were in $\mathrm{RB}-2.65 \%$, the smallest $-1.4 \%$ - in SR. The combination of ACE inhibitors+diuretic is in demand in $\mathrm{KK}-4.3 \%$, and minor demand $-1.0 \%$ - in MR. The obtained data prove differences in the preference of specialists at the level of specific regions of FSD. The use of ACE inhibitors/ ARBs with diuretics/CCB can be explained by the existence of many studies of these combinations, on the territory of the Russian Federation and beyond the limits of the country.

Combinations of $\beta$-blockers are among the most prescribed drugs in arterial hypertension, in combination with angina, post-infarct cardiosclerosis, heart failure. Indicators of acquisition of combinations of $\beta$-blockers with diuretics/CCB are shown in Figure 3. Despite the presence in regional pharmaceutical markets of combinations of modern selective substances (bisoprolol+hydrochlorothiazide/amlodipine; metoprolol+felodipine), the most purchased was a combination of atenolol+ chlorthalidone. Maximum values were observed in KK and $R S-$ $1.0 \%$, minimum - in SR $-0.2 \%$. The results are likely related to the high cost of selective medicines for patients.
The sales rates of $\mathrm{ARBs}+\mathrm{CCB}$ combinations, despite the presence of many indications for usage and a low risk of side effects, were not significant (Figure 4). The leader of the group was a combination of valsartan+amlodipine. The maximum demand in the $\mathrm{ZK}-1.2 \%$ and $R S$ (Yakutia) $-1.0 \%$. The three-component combination of valsartan+amlodipine +hydrochlorothiazide was most demanded in $R S-0.1 \%$. The observed trend can be explained by the small range of generic drugs and higher cost (more than 500 rubles (7.8 USD) per package) of drugs on the pharmaceutical market.

The leading therapeutic class in most FSD regions (except for $\mathrm{KK}$ ) is the combination of $\mathrm{ARBs}+$ diuretic (Figure 5). The most sought-after combination was losar$\tan +$ hydrochlorothiazide. The maximum share was in AR $7 \%$, the minimum share in $\mathrm{SR}-0.8 \%$. There is also a high demand for combinations of valsartan+hydrochlorothiazide $(2.4 \%$ in $\mathrm{AR})$. The interest in the combinations of losartan and valsartan can be explained by the overall increase in demand for the ARBs group, due to the absence of reduction of therapeutic effect and dry cough in patients.

The structure of implementation of combinations and $\mathrm{ACE}$ inhibitors+CCB is shown in Figure 6. Significant sales indicators of perindopril+amlodipine combination were observed in $\mathrm{KK}-1.5 \%, \mathrm{RB}-1.4 \%$. The largest share of lisinopril+amlodipine was in RS $-1.3 \%$ and the acquisition of ramipril+amlodipine was the largest in MR and $\mathrm{AR}-1.0 \%$ and $0.8 \%$, respectively. The demand for these combinations can be explained, the presence of

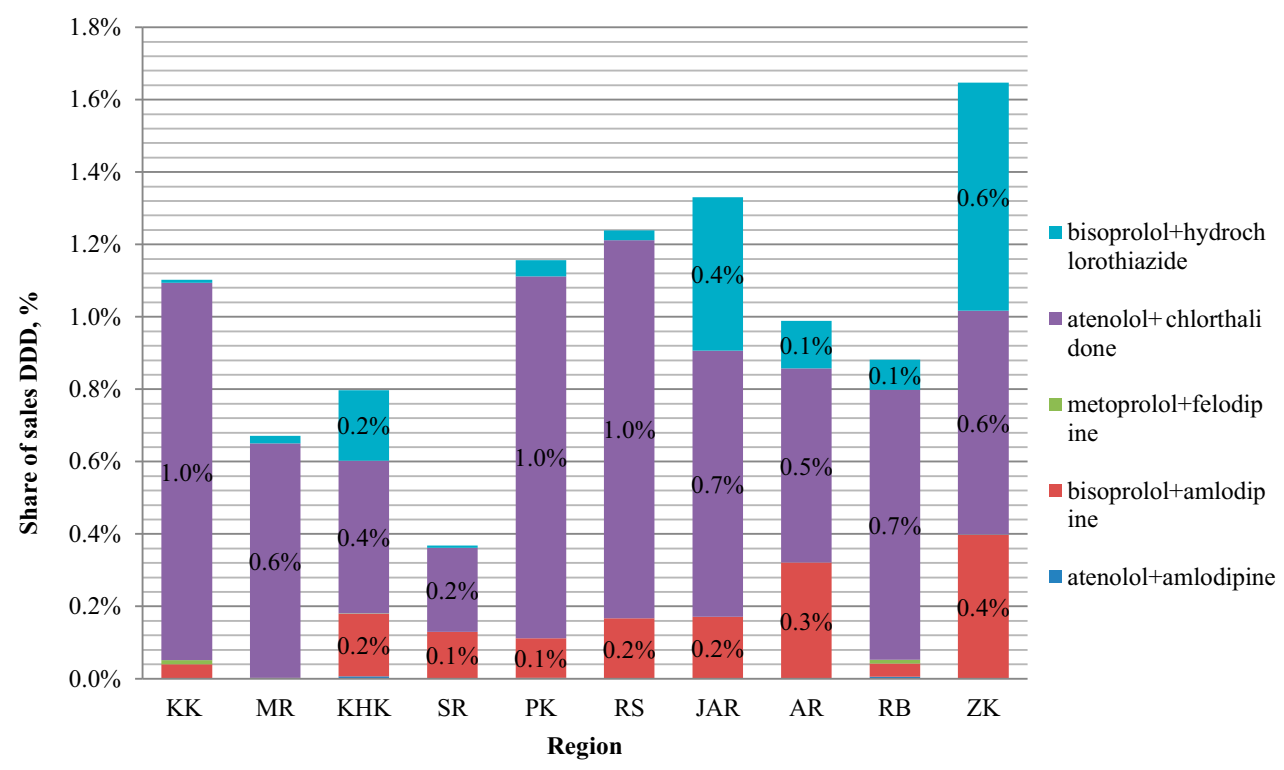

Figure 3 Structure of realization of DDD fixed-dose combinations of $\beta$-blockers. 


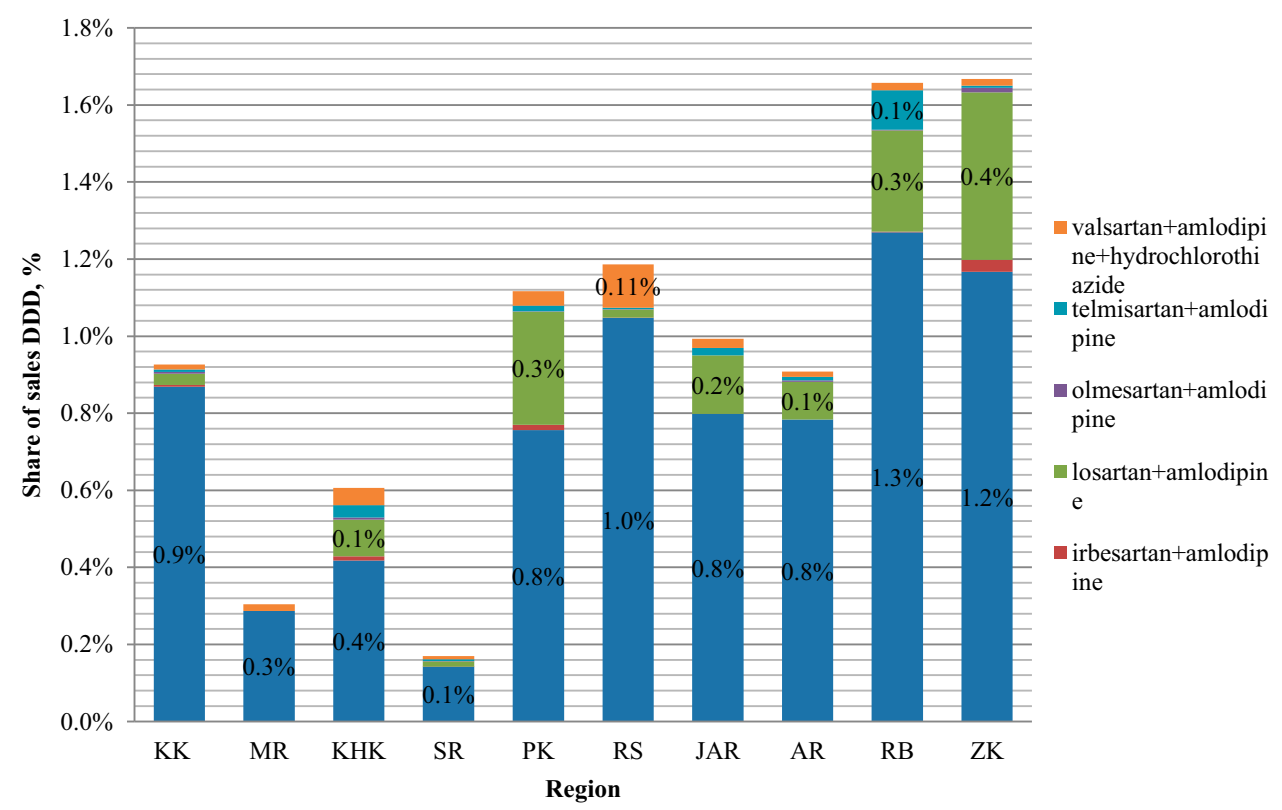

Figure 4 Structure of realization of DDD fixed-dose combinations of ARBs+CCB.

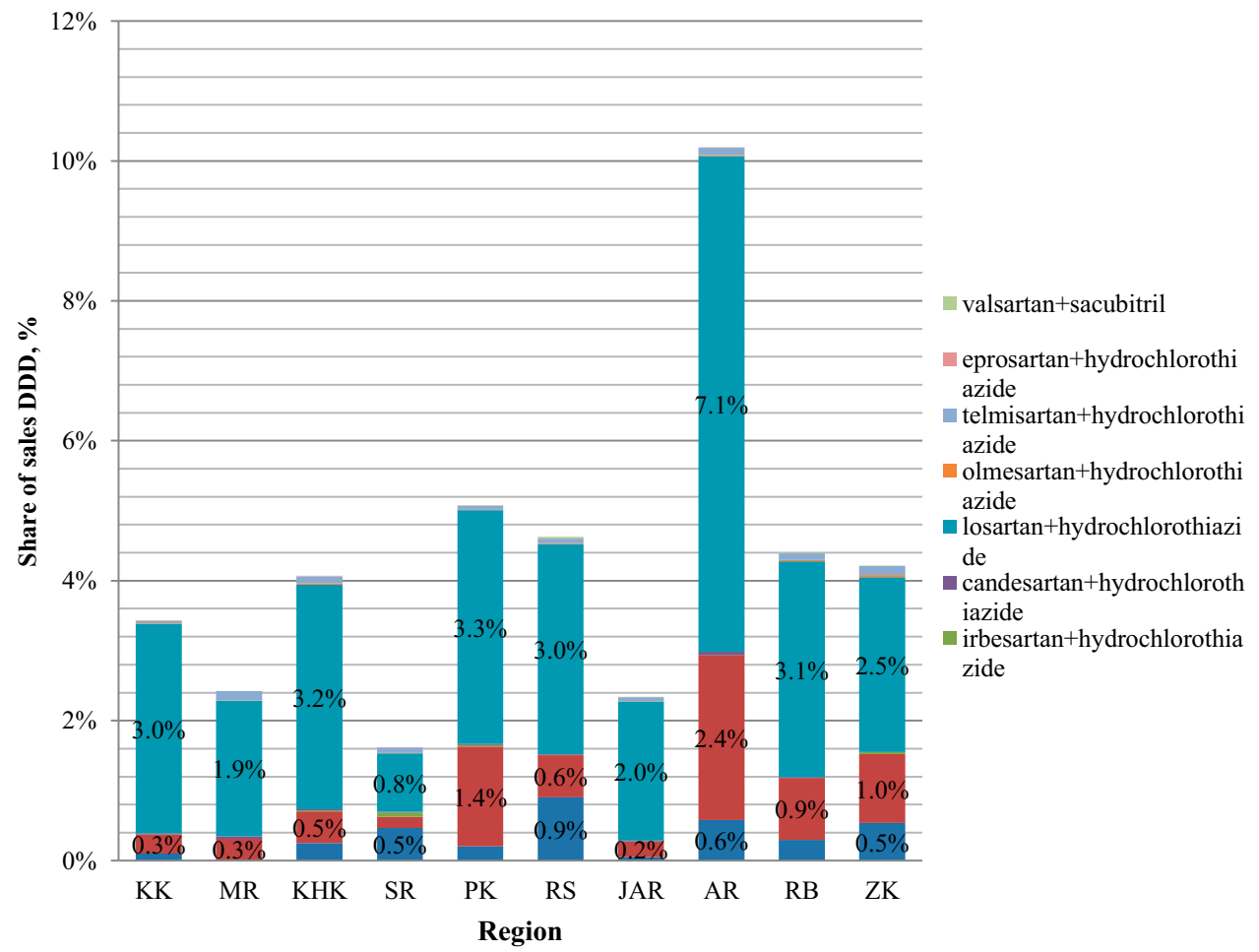

Figure 5 Structure of realization of DDD fixed-dose combinations of $A R B s+D$.

many generic drugs available at a price, and comprehensive study of substances in drugs.

One of the most demanded combinations remains ACE inhibitor+diuretic. The maximum sales shares of this therapeutic group were observed in KK. The preferences are shown in Figure 7. Based on the obtained data, it can be concluded that the combination of perindopril+indapamide is most commonly used in drug therapy of arterial hypertension. Maximum values in $\mathrm{KK}-3.2 \%$, minimum - in MR - $0.6 \%$. There is also a high demand for a combination of enalapril+hydrochlorothiazide in this group. The maximum figures were observed in $\mathrm{PK}-1.0 \%$. 


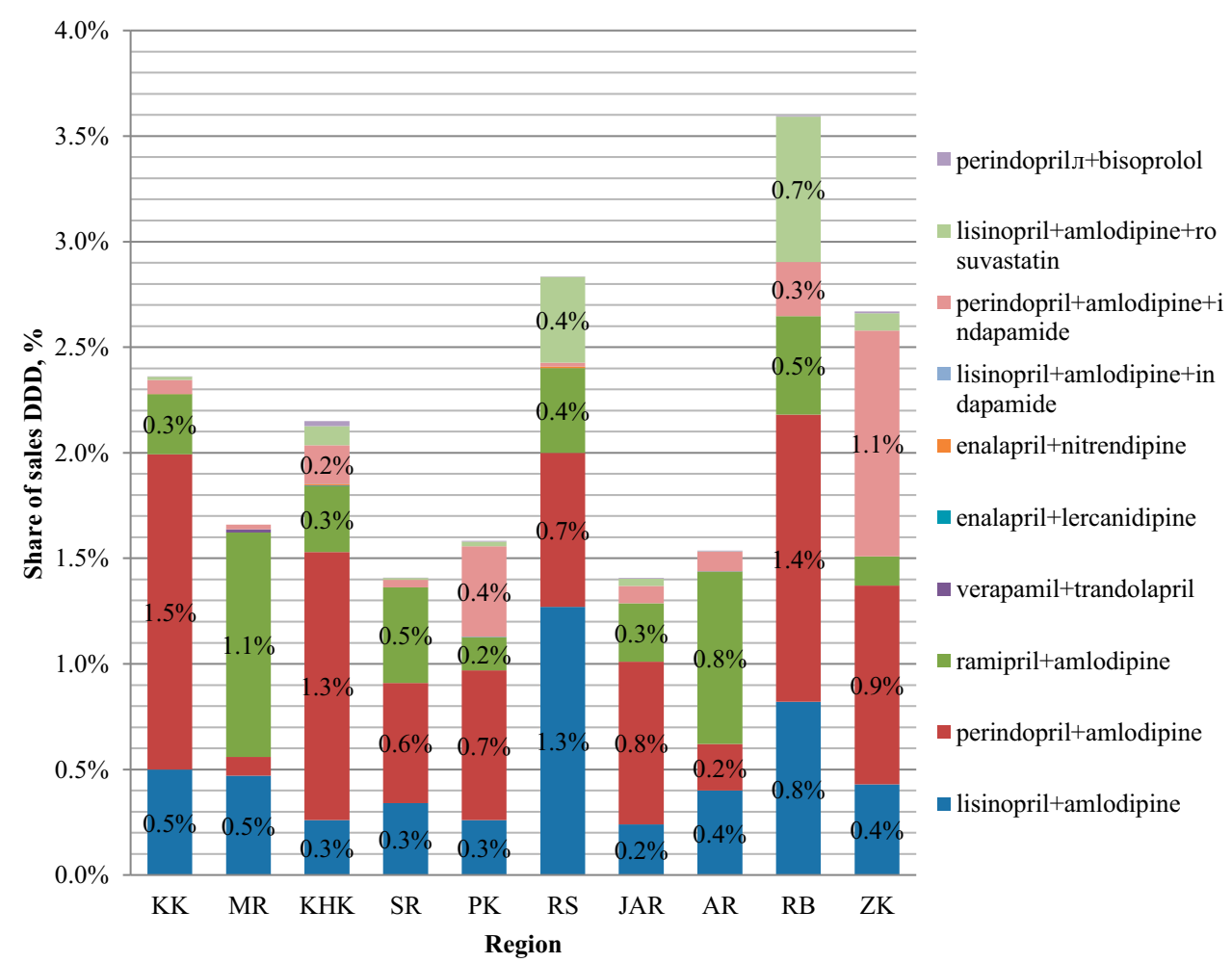

Figure 6 Structure of realization of DDD fixed-dose combinations of ACE inhibitors+CCB.

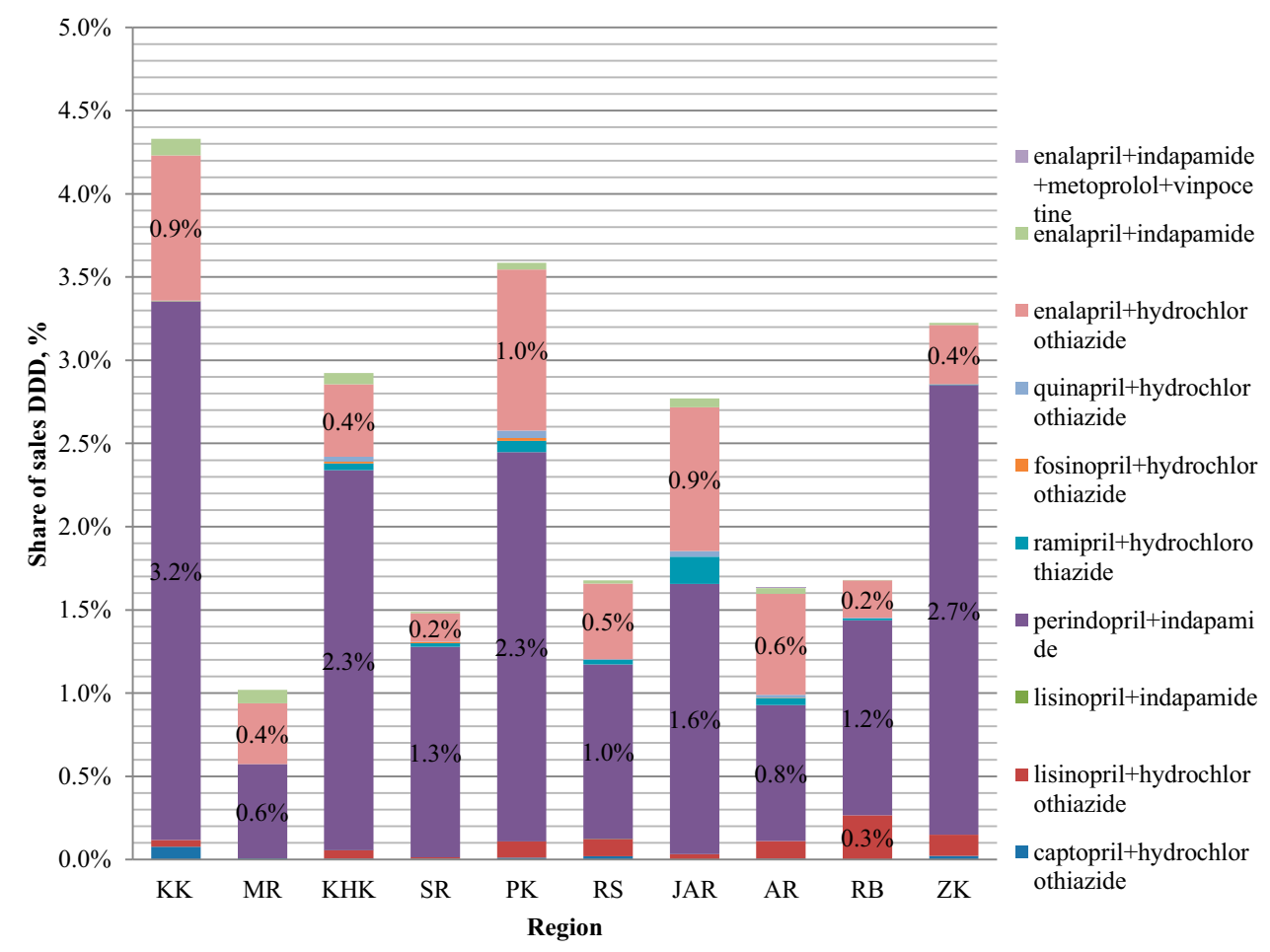

Figure 7 Structure of realization of DDD fixed-dose combinations of ACE inhibitors+diuretic.

To comparative analysis of the structure of the acquisition of antihypertensive fixed-dose combinations in all regions of FSD, at the next stage of the work we carried out statistical analysis. No significant differences were observed in the sales structure of the established defined daily dose in independent samples using the Kruskal- 
Wallis criterion: $p=0.099$ at a significance level of 0.05 .

There is no correlation of the structure (Spearman's rank correlation) of the acquisition with the region of the FSD: $r s-{ }_{0.01} 0.028_{0.06} ; \mathrm{p}$ (two-sided) $=0.56$. The results of the factor analysis were comparable, with a correlation of $0.53 ; \mathrm{p}$ (one-sided $)=0.133$.

In the territory of FSD, there were no such studies, including 10 regions at once and all therapeutic groups and fixed-dose combinations. In general, pharmacoepidemiological research in FSD-regions with low population density is rare. So, despite the absence of statistically significant differences in the structure of acquisition of drugs, we cannot extrapolate data to unexplored regions of the rest of the Russian Federation. And the usage of fixed-doses combinations remains low. Group leaders of fixed-dose combinations often depend on the pharmaceutical market presence of many generic drugs, as the price for them is generally lower, so they are more available to patients for regular usage.

\section{Conclusion}

The structure of patient's acquisition of fixed-dose antihypertensive combinations, subject to existing regional differences in 2018, is similar in all regions of FSD. The share of acquisition of combined drugs remains insignificant, contrary to the recommendations of the Russian Scientific Society of Cardiologists 2010-2019. Most in demand are combinations of atenolol+ chlorthalidone, valsartan+amlodipine, losartan+hydrochlorothiazide, perindopril/lisinopril/ ramipril+amlodipine, perindopril+indapamide. Threecomponent drugs, despite their convenience of use, are relatively rarely acquisitions by patients in all regions studied. Group leaders may vary from region to region, apparently due to the preferences of medical specialists, yet the differences are not statistically significant, which proves the unity of approaches to combined drug therapy for arterial hypertension.

\section{Compliance with the Principles of Ethics}

Research work meets the ethical standards developed in accordance with the Helsinki Declaration of the world medical Association "Ethical principles for conducting scientific medical research with human participation" as amended in 2000. The epidemiological study was conducted without the participation of humans and animals. The summary of the conducted study was considered and approved at the meeting of the Ethical Committee of The Far-Eastern State Medical University of June 05, 2018 (Protocol № 3).

\section{Disclosure}

The authors declare that there are no clear or potential conflicts of interest related to the publication of this article.

\section{References}

1. Federal State Statistics Service. Statistics. Official statistics. Population. Health care. Incidence. Incidence of socially significant diseases. Available from: https://gks.ru/folder/210/document/13218. Accessed May 5, 2020.

2. Chazova IE, Zhernakova $\mathrm{YuV}$ on behalf of the experts. Clinical guidelines. Diagnosis and treatment of arterial hypertension. Syst Hypertens. 2019;16(1):6-31. doi:10.26442/2075082X.2019.1.190179

3. Yusuf S, Lonn E, Pais P, et al.; HOPE-3 Investigators. Blood-pressure and cholesterol lowering in persons without cardiovascular disease. $N$ Engl J Med. 2016;374(21):2032-2043. doi:10.1056/NEJMoa1600 177.

4. Thomopoulos C, Parati G, Zanchetti A. Effects of blood-pressurelowering treatment in hypertension: 9. Discontinuations for adverse events attributed to different classes of antihypertensive drugs: meta-analyses of randomized trials. $J$ Hypertens. 2016;34 (10):1921-1932. doi:10.1097/HJH.0000000000001052

5. Lewington S, Clarke R, Qizilbash N, et al. Age-specific relevance of usual blood pressure to vascular mortality: a metaanalysis of individual data for one million adults in 61 prospective studies. Lancet. 2002;360:1903-1913. doi:10.1016/s0140-6736(02)11911-8

6. De Buyzere ML, Clement DL. Management of hypertension in peripheral arterial disease. Prog Cardiovasc Dis. 2008;50(4):238-63.41. doi:10.1016/j.pcad.2007.08.001

7. Corrao G, Zambon A, Parodi A, et al. Discontinuation of and changes in drug therapy for hypertension among newly-treated patients: a population-based study in Italy. J Hypertens. 2008;26(4):819-824. doi:10.1097/HJH.0b013e3282f4edd7

8. MacDonald TM, Williams B, Webb DJ, et al. British Hypertension Society Programme of Prevention And Treatment of Hypertension With Algorithm-based Therapy (PATHWAY). Combination therapy is superior to sequential monotherapy for the initial treatment of hypertension: a double-blind randomized controlled trial. J Am Heart Assoc. 2017;6(11):pii:e006986. doi:10.1161/JAHA.117.006986

9. Wald DS, Law M, Morris JK, et al. Combination therapy versus monotherapy in reducing blood pressure: meta-analysis on 11,000 participants from 42 trials. Am J Med. 2009;122:290-300.68. doi:10.1016/j.amjmed.2008.09.038

10. Corrao G, Parodi A, Zambon A, et al. Reduced discontinuation of antihypertensive treatment by two-drug combination as first step. Evidence from daily life practice. J Hypertens. 2010;28:1584-1590. doi:10.1097/HJH.0b013e328339f9fa

11. Gupta AK, Arshad S, Poulter NR. Compliance, safety, and effectiveness of fixed-dose combinations of antihypertensive agents: a meta-analysis. Hypertension. 2010;55(2):399-407. doi:10.1161/ HYPERTENSIONAHA.109.139816

12. Mirzoyan A. Welcome to the chain. Pharm Messenger. 2016;11(840). Available from: https://pharmvestnik.ru/articles/dodro-pozhalovatj-vset.html. Accessed May 5, 2020

13. Yakovleva NF. Sociological Research: Educational Manual. $2^{\text {nd }}$ ed. Stern.M. FLINTA; 2014:25. Available from: http://www.kspu.ru/ upload/documents/2015/10/19/9510fc4ecabf2052ab738becde976ef7/ sotsiologicheskoe-issledovanie.pdf. Accessed May 5, 2020.

14. List of DDDs combined products. Available from: https:/www. whocc.no/ddd/definition_and_general_considera/\#ddds2. Accessed May 5, 2020. 


\section{Publish your work in this journal}

ClinicoEconomics and Outcomes Research is an international, peerreviewed open-access journal focusing on Health Technology Assessment, Pharmacoeconomics and Outcomes Research in the areas of diagnosis, medical devices, and clinical, surgical and pharmacological intervention. The economic impact of health policy and health systems organization also constitute important areas of coverage. The manuscript management system is completely online and includes a very quick and fair peer-review system, which is all easy to use. Visit http://www.dovepress.com/testimonials.php to read real quotes from published authors.

Submit your manuscript here: https://www.dovepress.com/clinicoeconomics-and-outcomes-research-journal 